\title{
Reaction Monitoring of Imine Synthesis Using Raman Spectroscopy
}

\author{
Moonkwon Lee, Hyesung Kim, Hakjune Rhee, and Jaebum Choo ${ }^{*}$ \\ Department of Chemistry, Hamang Universin, Ansan +25-791. Korea \\ Recened December 6, 2002
}

\begin{abstract}
Laser-induced Raman spectroscopy has been utilized to demonstrate its feasibility for studying the kinetics of imine formation in chloroform solvent. The imine formation. by the nucleophilic addition of primary amine to the carbonyl group of ketone. has been monitored at ten minute intervals for eight hours. The intensity of the $\mathrm{C}=\mathrm{O}$ stretching mode at $1684 \mathrm{~cm}^{-1}$ was measured to determine the rate constant of the reaction. In order to correct the sample-to-sample fluctuations in Raman peak area. this peak was normalized to the $\mathrm{C}-\mathrm{Cl}$ bending peak at $666 \mathrm{~cm}^{-1}$. By the peak area change during the course of reaction. the second order rates at three different temperatures have been determined. The substituent effects on the $\pi$ conjugations of imine product have also been investigated. On the basis of Raman frequency shifts. the delocalization properties of the aromatic sy stem modified by substitution of a hỵdrogen atom with $-\mathrm{Cl}$ and $-\mathrm{CH}_{3} \mathrm{O}$ groups could be clearly understood.
\end{abstract}

Key Words : Raman spectroscopy. Reaction monitoring. Imine șyntheșis

\section{Introduction}

Imine formation is a very important chemical reaction because of its relevance to biological process. ${ }^{l}$ Many biological reactions involve initial binding of carbonyl compound to an enzyme through imine formation. In order to monitor the process of imine formation. a highly sensitive detection method is required. Thin layer chromatography (TLC) is generally used to monitor the extent of imine formation. However. since the silica gel coating on the glass plate acts as an acid catalyst the imine product is partly hydrolyzed to the corresponding ketone and so it is difficult to accurately monitor the extent of imine formation using TLC.

Laser-induced Raman spectroscopy is a powerful tool for the in-situ monitoring of organic reactions. which does not interrupt the reaction processes in most cases. ${ }^{3-5}$ In the present study, the imine formation by the nucleophilic addition of primary amine to the carbonyl group of ketone has been monitored employing Raman spectroscopy. Due to the moderate reaction rate and detection capability of Raman signal the imine formation reaction is considered as a very good model system for the Raman study. In order to monitor the variation of Raman peaks during the course of reaction. time-dependent Raman spectra were accumulated for eight hours with ten-minute intervals

Together with reaction monitoring of the imine formation. its substituent effect has also been investigated. The aromatic syrstem modified by substitution of hydrogen atom to different substituents is an interesting model since it reveals different nature of aromatic $\pi$ system with unsaturated functional groups ${ }^{6.7}$ On the basis of the Raman spectral data. the properties of intramolecular interactions and the reactivities of aromatic compounds can be predicted. Here we demonstrate the feasibility of Raman spectroscopy for

\footnotetext{
${ }^{*}$ To whom correspondence should be addressed. e-mail: jbchoo ahanyang.ac.ks
}

monitoring the imine formation process as well as the substituent effect on its $\pi$ conjugation.

\section{Experimental and Computational Section}

Raman measurements were performed with a Renishaw 1000 Raman microscope system. Spectra Phỵsics argon ion laser at $514.5 \mathrm{~nm}$ was used as the excitation source. The laser power was approximately $20 \mathrm{~mW}$. A macro-sample chamber equipped with a $10 \mathrm{x}$ objective lens was used to focus the laser beam to the sample. Rayleigh line was removed from the collected Raman scattering by a holographic notch filter in the collection path. Raman scattering was detected with a charge coupled device (CCD) camera and spectral resolution was $2 \mathrm{~cm}^{-1}$. Mid-infrared spectra were recorded with a Bio-Rad FTS-6000 interferrometer operating at a resolution of $1 \mathrm{~cm}^{-1}$. A cryogenic MCT detector and KBR windows were used for the infrared measurements.

All the chemical reagents. including acetophenone aniline. $p$-chloroaniline. $p$-methoxyaniline and chloroform. were purchased from Aldrich chemical and used without further purification. The reaction product was identified using FTIR. Raman and NMR spectroscopy. In order to monitor the reaction process. time-dependent Raman measurements were accomplished in a $200 \mathrm{~mL}$ volumetric flask in a temperature-controlled water bath. Molecular sieves were used to remove water since the product imine is reversely hydrolyzed to the corresponding acetophenone and aniline if water is not effectively removed during the course of reaction. About $1 \mathrm{~mL}$ of sample was periodically transferred to a quartz cell and quenched for Raman measurements. Raman spectra were accumulated with the integration time of 20 seconds. All spectral manipulations were performed using GRAM 32 software from Galactic Industries Corporation.

The Raman frequencies of imine were calculated using the B3LYP method. ${ }^{8-10}$ On the basis of the computational results at the B3LYP/6-31G(d) level, the vibrational modes of each 
molecule were assigned and compared with the observed spectra. All the calculations were performed using the GAUSSIASN98 program package ${ }^{\text {ll }}$ implemented on an alphacluster computer system. The GAUSSVIEW program was also used to visualize the vibrational modes assisting the assignment of spectra.

\section{Results and Discussion}

Reaction Monitoring of Imine Formation Using Raman Spectroscopy. This experiment was carried out to establish whether it would be possible to monitor in-situ imine formation reaction using Raman spectroscopy. The model reaction under investigation is the imine formation shown in Scheme 1

Molecular sieves were used in order to effectively remove water during the course of reaction. Figure 1 shows the Raman spectra of chloroform solvent. two reactants and fully converted product. $N$-(1-phenylethylidene)-aniline. Many of the differences in these spectra arise from the intensity changes in the $1500-1800 \mathrm{~cm}^{-1}$ region. In order to monitor the spectral changes during the course of reaction. Raman spectra were accumulated for ten seconds at ten minute intervals over eight hours. These Raman spectra are shown in Figure 2. The Raman spectra show the intensity changes of the peaks at $1596 \mathrm{~cm}^{-1} .1639 \mathrm{~cm}^{-1}$ and $1684 \mathrm{~cm}^{-1}$ for the ring $\mathrm{C}=\mathrm{C}$ stretching. $\mathrm{C}=\mathrm{N}$ stretching and $\mathrm{C}=\mathrm{O}$ stretching modes. respectively. Figure 3 demonstrates their peak area variations with time. It shows that the $\mathrm{C}=\mathrm{O}$ stretching

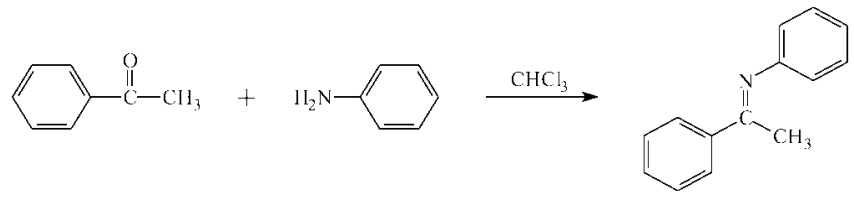

Scheme 1

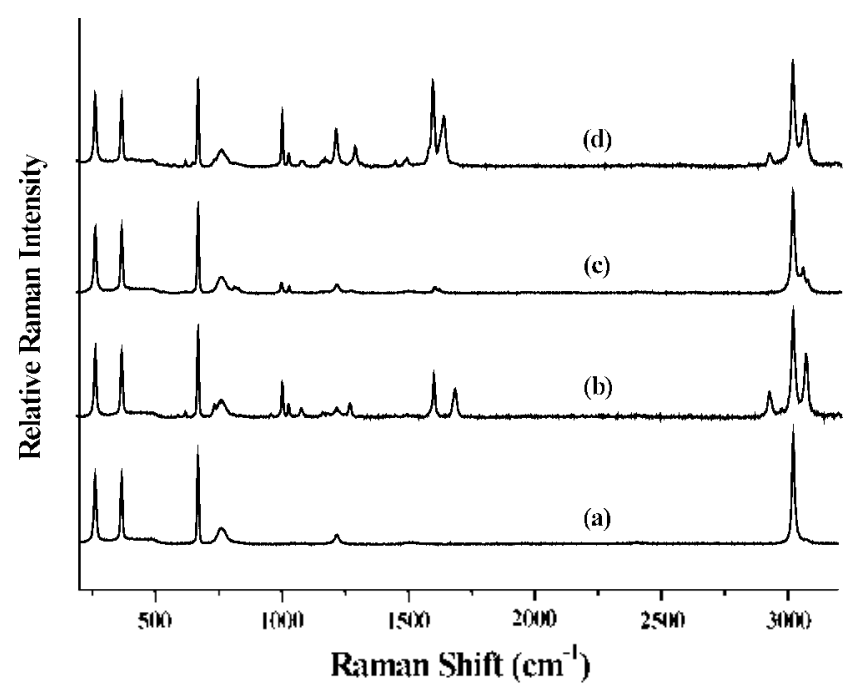

Figure 1. Raman spectra of (a) chlorofonn solvent only, (b) acetophenone in chloroform, (c) aniline in chlorofom, and (d) fully converted product, $\mathrm{V}$-( 1 -phenylethylidene)-aniline, in chloroforin.

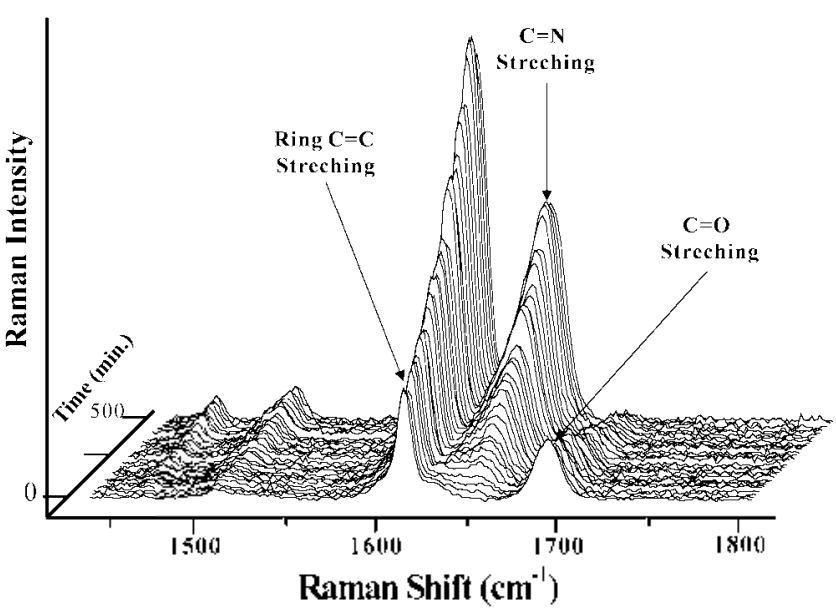

Figure 2. Time-dependent Raman spectra of the product, $\mathrm{N}$-( Ipheny lethylidene -aniline, showing loss of the $1684 \mathrm{~cm}^{-1}$ peak and gains of the $1596 \mathrm{~cm}^{-1}$ and $1639 \mathrm{~cm}^{-1}$ peaks in chloroform. Reaction temperature was $25^{\circ} \mathrm{C}$ and time interval for each spectrum is 10 mirl.

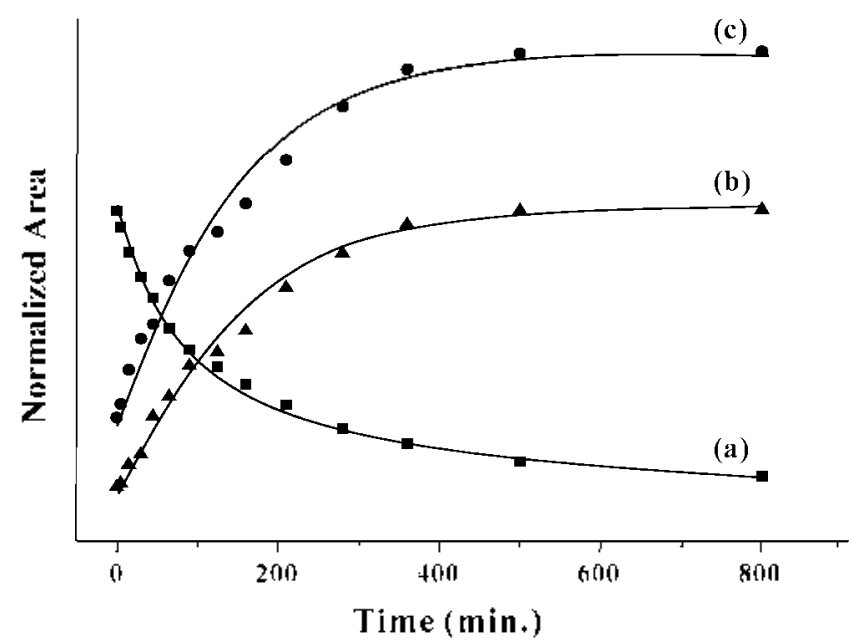

Figure 3. Peak area variations of $\mathrm{N}$-( 1 -phenylethylidene)-aniline formation for three different vibrational modes in Figure 2: (a) $\mathrm{C}=\mathrm{O}$ stretching mode at $1684 \mathrm{~cm}^{-1}$, (b) $\mathrm{C}=\mathrm{N}$ stretching mode at $1639 \mathrm{~cm}^{-1}$, and (c) ring $\mathrm{C}=\mathrm{C}$ stretching mode at $1596 \mathrm{~cm}^{-1}$.

peak of acetophenone decreases in intensity with time and completely disappears after eight hours. The $\mathrm{C}=\mathrm{N}$ stretching peak of the product $N$-(1-phenyletlyy lidene)-aniline. steadily becomes stronger during the course of reaction demonstrating that the reactants are fully converted to the product. In addition, the intensity of ring $\mathrm{C}=\mathrm{C}$ stretching peak increases with the formation of imine. This change indicates that the ring stretching mode is substantially affected by the conjugation of $\pi$ electrons. When the $\pi$ electrons are effectively delocalized through the system. the Raman intensity of a ring $C=C$ stretching mode is increased due to a $\pi$ electron conjugation. In the case of the imine. the $\pi$ electron conjugation is maximized by long $\pi$ electron delocalization between two phenyl rings through the $-\mathrm{C}=\mathrm{N}$ - bridging group. As a result the Raman intensity of ring $\mathrm{C}=\mathrm{C}$ stretching mode gradually increases during the formation of imine. 


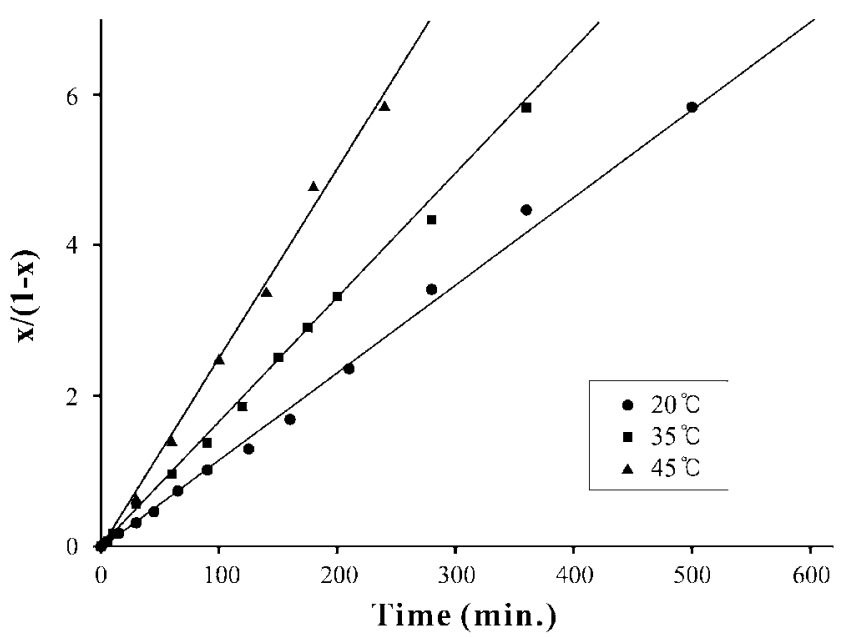

Figure 4 . Plots of conversion ratio to determine the second order rate constants at three different temperatures. Here $x$ is the degree of conversion.

Among these three peaks. the disappearance of $\mathrm{C}=\mathrm{O}$ stretching mode at $1684 \mathrm{~cm}^{-1}$ was used to determine the rate constant of the reaction since its disappearance after a long reaction time demonstrates that complete conversion can be detected by the Raman teclunique. In order to correct the sample-to-sample fluctuations in Raman peak area. this peak was normalized to the $\mathrm{C}-\mathrm{Cl}$ bending peak at $666 \mathrm{~cm}^{-1}$. This is a suitable Raman peak to be selected as an internal standard since the peak is very consistent regardless of the course of reaction.

The general $n$th order model was applied and a reaction order of 2.0 was determined. The plots to determine the second order rate constants at $25^{\circ} \mathrm{C} .35^{\circ} \mathrm{C}$ and $45^{\circ} \mathrm{C}$ are shown in Figure 4. All the plots show very good linear correlation coefficients over 0.99 . The second order rate constants at those temperatures are also shown in Table 1 with the correlation coefficient values for the straight-line fits.

Substituent Effects on the Conjugation of Imine Product. Together with reaction monitoring of the imine formation. substituent effects on the $\pi$ conjugation of imine product have also been investigated. On the basis of Raman frequency shifts. it is possible to rationalize the properties of $\pi$ conjugation for different imine products. The model compounds under investigation are three different aromatic $\pi$ systems modified by substitution of hydrogen atom by $-\mathrm{Cl}$ and $-\mathrm{CH}_{3} \mathrm{O}$ groups. Each product was made by the reaction of acetophenone and aniline with different substituent $\mathrm{X}$ as

Table 1. Reaction temperatures, concentrations, and comresponding second order rate constants for the imine fomation in chloroform

\begin{tabular}{cccc}
\hline $\begin{array}{c}\text { Temperature } \\
\left({ }^{\circ} \mathrm{C}\right)\end{array}$ & $\begin{array}{c}\text { Initial } \\
\text { concentration } \\
(\mathrm{M})\end{array}$ & $\begin{array}{c}\text { Rate constant } k \\
\left(\mathrm{M}^{-1} \mathrm{~min}^{-1}\right)\end{array}$ & $\begin{array}{c}\text { Cortelationt } \\
\text { coefficient } \\
\mathrm{R}\end{array}$ \\
\hline 25 & 0.72 & $1.06 \times 10^{-2}$ & 0.992 \\
35 & 0.72 & $1.77 \times 10^{-2}$ & 0.990 \\
45 & 0.72 & $2.40 \times 10^{-2}$ & 0.992 \\
\hline
\end{tabular}

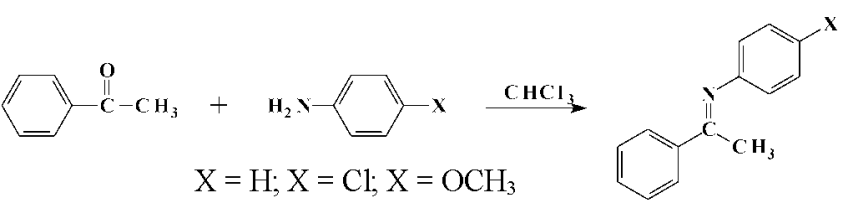

Scheme 2

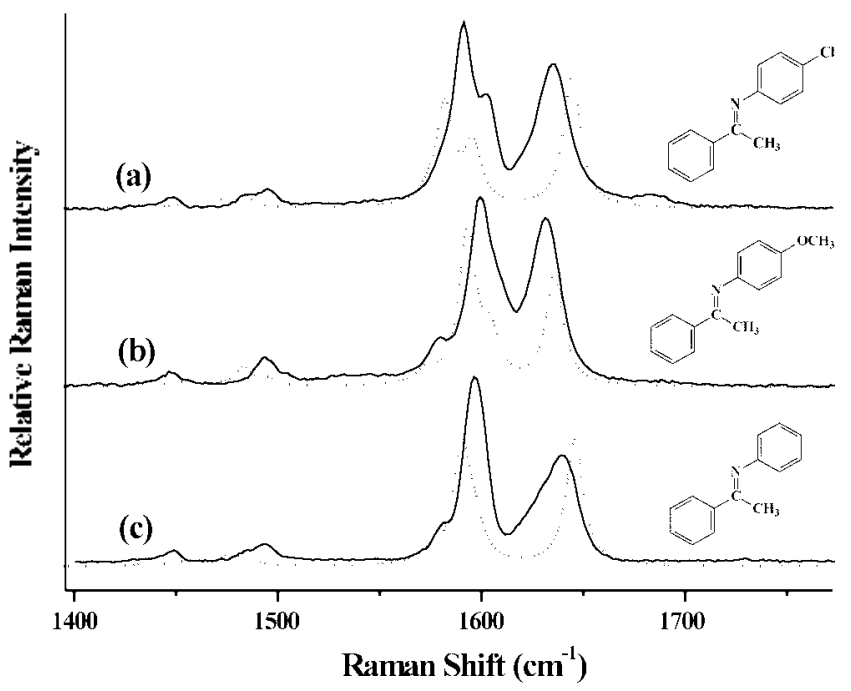

Figure 5. Raman spectra of three different substituted imines: (a) p-chloro- $\mathrm{N}$-(I-pheny lethylidene)-aniline, (b) $\mathrm{N}$-(I-pheny lethylidene)-anisidine, and (c) N-(1-phenylethylidene)-aniline. The dotted spectra are the simulated Raman spectra at the B.LYP/6$3 I G(d)$ level.

shown in Scheme 2.

Raman frequency shift strongly depends on the $\pi$ electron conjugation between two phenyl rings through the $-\mathrm{C}=\mathrm{N}-$ bridging group. which will be affected by different substituents X. Figure 5 shows the Raman spectra of three different substituted imines.

Table 2 shows the characteristic Raman frequencies for three imine products with different substituent $\mathrm{X}$. When the electron-donating $-\mathrm{CH}_{3} \mathrm{O}$ group is attached to the benzene ring. the strongest ring $\mathrm{C}=\mathrm{C}$ stretching peak shifts to a higher frequency. This is because the electron donation from the $-\mathrm{CH}_{3} \mathrm{O}$ group to the benzene ring enhances the $\pi$ electron conjugation in the ring. As a result. the $\mathrm{C}=\mathrm{C}$ stretching force force field increases. On the contrary, the corresponding peak shifts to a lower frequency when the electron withdrawing $-\mathrm{Cl}$ group is attached to the ring due to a decreased force field.

Table 2. Observed and calculated Raman frequencies for the ring $\mathrm{C}=\mathrm{C}$ stretching modes for three imine products with different substituents

\begin{tabular}{lcc}
\hline Product name & Observed & Calculated \\
\hline N-(1-Phenylethylidene)-aniline & 1596 & 1590 \\
N-(1-Phenylethylidene)-anisidine & 1600 & 1593 \\
p-Chloro-X-(1-Phenylethylidene)-aniline & 1591 & 1582 \\
\hline
\end{tabular}

B3LYP:6-3IG(d) level: Vibrational frequency was scaled by 0.9614 . 


\section{Conclusion}

It has been demonstrated that laser-induced Raman spectroscopy is a powerful tool for the in-situ monitoring of organic reactions. which does not interrupt the reaction processes. This technique has been successful for monitoring the inine formation. but it could be applicable to many kinds of organic reactions. It allows highly reproducible measurements and straightforward to handle.

The Raman technique also offers great advantages for probing the chemical and structural properties of a sample. In the present study: the substituent effects on the $\pi$ conjugations of different imine products have been investigated. When the electron-donating $-\mathrm{CH}_{3} \mathrm{O}$ group is attached to the benzene ring. the ring $\mathrm{C}=\mathrm{C}$ stretching peak shifts to a higher frequency since the electron donation from the $-\mathrm{CH}_{3} \mathrm{O}$ group to the benzene ring enthances the $\pi$ electron conjugation in the ring. On the contrary, the corresponding peak shifts to a lower frequency when the electron withdrawing - $\mathrm{Cl}$ group is attached to the ring due to a decreased force field.

Acknowledgment. This work is supported by the Korea Science and Engineering Foundation (Grant number R142002-004-01000) and in part by the Hanyang University Research Fund of the academic year 2002.

\section{References}

1. (a) Vdovenko. S. I: Gerus. I. I.: Wojcik. J. J. Phns. Org Chem.
2001. 14, 533. (b) Kohler, M. A.; Richarz, W. Chen. Engng. Sci. 1985. 10. 1983.

2. Smith. M. B.: March. J. Adranced Organic Chemisty: Reactions, Mechanisms. and Structures. $5^{\text {th }}$ Ed.: Tohn Wileys \& Sons. Ltd.: Chichester. UK. 2001; pp 1177-78 and references therein.

3. Bruneel. J. L.: Lassegues. J. C.: Sourisseau. C. J. Raman Spectrose. $2002,33.815$.

4. Jeon. S.: Woo. J.: Kyong. J. B.: Choo. I. Bull Korean Chem Soc. 2001. 22. 1264.

5. Jeon. S.: Choo. T.: Kim. S.: Kwon. Y.: Kim. J.: Lee. Y.: Chung. H. J. Hol Struct. 2002, 609. 159.

6. Korovenicheva. I. K: Furin. G. G:; Yakobson. G. G. J. Mlol. Struct 1984, 114. 395 .

7. Schmid. E. D.: Schlenker. P.: Brand. R. R. M. J. Raman Spectrosc. 1977.6.314.

8. Scott. A. P.: Radom. L. J. Plys. Chem. 1996. 100. 16502.

9. Lee C: Yang. W: Parr. R. G. Phus. Rev 1988. B37.785.

10. Becke. A. D. J. Chem. Phns. 1993, 98, 5648.

11. Frisch. M. J:- Trucks. G. W.: Schlegel, H. B:- Scuseria, G. E.: Robb. M. A.; Cheeseman. J. R.: Zakrzewski. V. G.; Montgomery. J. A.: Stratmann. R. E.: Burantt. J. C.: Dapprich. S.: Millam. J. M.: Daniels. A. D.: Kudin. K. N.: Strain. M. C.: Farkas. O.: Tomasi. T. Barone. V: Cossi. M.: Cammi. R.: Mennucei. B.: Pomelli. C.: Adamo. C: Clliford. S.: Ochterski. J.: Petersson. G. A.: Ayala. P. Y.: Cui. Q.: Morokuma K.: Malick, D. K.: Rabuck, A. D.: Raghavachari, K: Foresman, J. B.: Cioslowsski, J.: Ortiz, J. V.; Stefanor. B. B.: Liu. G.: Liashenko. A.: Piskorz. P.: Komaromi. I.: Gomperts. R.: Martitl. R. L.: Fos. D. J.: Keith. I.: Al-Laham. M. A.: Peng. C. Y.: Nanayahkara. A.: Gonzalez. C.: Challacombe. M.; Gill, P. M. W: Johnson. B. G.; Chen, W: Wong. M. W: Andres. J. L.; Head-Gordon, M.: Replogle, E. S.; Pople. J. A. Gatssian 98. Revision A.7: Gaussian Ine: Pittsburg PA. 1998. 